\title{
Modern Standard Arabic in the Minds of Diglossic Speakers of Arabic
}

\author{
Moh'd A. Al-Omari \\ The Hashemite University \\ Zarqa, Jordan
}

\begin{abstract}
This paper reinvestigates the cognitive relevance of Arabic diglossia in spoken word recognition through replicating Ibrahim \& Aharon-Peretz's study (2005) on a more typical diglossic situation of Arabic. The present study targets native speakers of Jordanian colloquial Arabic rather than Arabic-Hebrew bilinguals of Israel. A priming lexicaldecision task was designed and conducted on a group of 40 literate native speakers of Jordanian Colloquial Arabic. The experiment compared participants' reaction times to Jordanian colloquial Arabic (JCA) words and Modern Standard Arabic (MSA) words when primed by semantically related and unrelated words from the same and the other variety of Arabic. Results revealed a processing advantage for JCA words relative to MSA words. The priming effects were larger when the related primes were presented in JCA relative to the priming effects of the MSA primes. The research findings support the proposal that MSA is an L2 for diaglossic speakers of Arabic (Ibrahim \& Aharon-Peretz, 2005). The findings reject the proposal that MSA is an exceptional L2 for Arabic-Hebrew bilingual of Israel, a thing that cannot be generalized to the rest of the Arab-speaking world (Boudelaa \& Marslen-Wilson, 2013).
\end{abstract}

Keywords: Arabic word recognition, Arabic diglossia, bilingualism.

\section{Introduction}

Native speakers of Arabic acquire their language in the special linguistic context of diglossia (Ferguson, 1959), where different spoken dialects of Arabic coexist with the more formal variety known as Modern Standard Arabic (AbuRabia, 2000; Maamouri, 1998). The two varieties show some divergences and convergences at all levels of linguistic description. Modern Standard Arabic (MSA) is used in formal situations such as public occasions, religious contexts, media, and press. It is no one's native language, and Arabs usually learn it in school. ${ }^{1}$ MSA is the language of Arabic literacy (i.e., the language of reading and writing). Alternatively, the different varieties of colloquial Arabic (CA) are acquired early and used in everyday situations when people communicate with each other. Reading and writing in CA varieties is not common and limited to some aspects of social media (e.g., text messages, Twitter, Facebook; Al-Khatib \& Sabbah 2008; Mostari 2009). In such contexts, native speakers of Arabic transliterate spoken colloquial Arabic words with MSA letters, Romanized letters or a combination of the two. While all native speakers of Arabic use the same MSA variety, their spoken dialects vary from one state to another and even in different regions of the same state.

The linguistic situation in Jordanian society is a typical example of Arabic diglossia (Al-Saidat, 1999; Suleiman, 1985). Despite the similarities between Jordanian colloquial Arabic (JCA) and MSA, the two varieties differ considerably in their phonology, phonetics, morphology, and lexicon (Al-Sughayer, 1990; Holes, 2004; Laks \& Berman, 2014). Taking into account the linguistic and experiential differences between CA and MSA, it is possible that literate native speakers of Arabic are actual unbalanced bilinguals.

\section{Scope of the Study}

This paper reexamines the claim that MSA is a second language for diglossic speakers of Arabic (Ibrahim \& AharonPeretz, 2005). The current study replicates Ibrahim and Aharon-Peretz's (2005) methodology on a different population of Arabic society. The targeted subjects are native speakers of Jordanian Arabic rather than Arabic-Hebrew bilinguals of Israel. The Arabic-Hebrew bilinguals of Israel live on the West Bank of the Jordan River and speak Palestinian colloquial Arabic (PCA) while Jordanians live on its JCA.

\footnotetext{
${ }^{1}$ This does not mean that native speakers of Arabic are not exposed to MSA before the school age. Some native speakers of Arabic experience MSA, from a more receptive standpoint, before they start formal schooling by watching MSA TV cartoons, early reading, and religion learning. However, it is beyond the scope of this study to examine any possible relationship between how early MSA is exposed to and the diglossic lexical access and representation.
} 
Although the two varieties CA have some remarkable differences, there is a common impression that Palestinian and Jordanians speak more or less the same dialect, which is classified as the Southern Levantine variety of Arabic. Nonetheless, Arabic-Hebrew bilinguals of Israel were born and grew up in a different sociolinguistic situation, where Hebrew is the dominant language of education and public occasions in Israel (Amara, 2006; Boudelaa \& MarslenWilson, 2013). The linguistic situation of Arabic diglossia could be more stable in Jordan, as MSA is the only official language used.

In this study, I conducted an auditory translation priming experiment, similar to Ibrahim and Aharon-Peretz's early experiment (2005). The experiment measured participants' reaction times to spoken JCA and MSA target words in semantically related and unrelated conditions. Bilingual research showed that unbalanced bilinguals, who are unequally proficient and practiced in the two languages, react to their L1 words faster than they respond to their L2 words. Similar research also revealed stronger translation priming effects from L1 to L2 but weaker translation priming effects from L2 to L1 (e.g. Jiang, 1999; Schoonbaert et al., 2009; Schoonbaert et al., 2011). Some research did not even report any translation priming effects from L2 to L1, proposing a qualitative difference in how bilinguals access the semantic representations for the vocabulary of both languages (e.g., Finkbeiner et al., 2004; Jiang \& Forster, 2001). Sabourin et al. (2014) concluded that only simultaneous and early sequential English-French bilinguals activate the lexical items of their L1 when they see their L2 translation equivalents. The authors found that late English-French bilinguals do not have shared sematic representations for their L1 and L2 lexical items, even if they are as proficient as early bilinguals. Sabourin and colleagues' results suggest that the age of acquisition is the most relevant factor in L2-L1 semantic activation. The asymmetrical translation priming effect between L1-L2 and L2-L1 is usually introduced as evidence for the assumption that L1 and L2 words do not activate their semantic representations to the same degree (Kroll \& Stewart, 1994; Kroll et al., 2002; Talamas et al., 1999). That is, unbalanced bilinguals associate their L2 vocabulary to meaning through loose and weak links, or maybe indirectly through the L1 lexicon while they map their L1 words to their concepts in a robust manner. This study will determine whether JCA vocabulary has a processing advantage over MSA vocabulary. A positive answer to this question suggests that MSA is an L2 for diglossic speakers of Arabic asIbrahim and Aharon-Peretz (2005) propose. A negative answer to this question supports the proposal that MSA is an exceptional L2 for Arabic-Hebrew bilingual of Israel, a thing that cannot be generalized to the rest of the Arabspeaking world (Boudelaa \& Marslen-Wilson, 2013).

\section{Literature Review: Arabic Diglossia in Word Recognition}

Ibrahim and Aharon-Peretz (2005) raised the question of whether learning MSA is like learning the formal register of one's native language or it is more like learning an L2. To answer this question, the authors addressed the status of MSA for literate native speakers of Arabic from a psycholinguistic perspective. ${ }^{2}$ The researchers conducted two semantic priming experiments on two homogeneous literate groups of Palestinian Arabic-Hebrew bilinguals from Israel. The researchers compared PCA, MSA, and Hebrew words in semantically-related (i.e., translation) and unrelated conditions. In the first priming experiment, the targets were always PCA words and the primes were either in PCA (i.e., intra-language stimuli: PCA-PCA) or in one of the other two languages (i.e., cross-language stimuli: MSAPCA, Hebrew-PCA). The results showed that Arabic-Hebrew bilinguals reacted to the target words (always PCA) in the semantically-related (i.e., translation) condition faster and more accurately than the target words in the semantically unrelated condition, regardless of the language of the prime. However, the priming effect was three times as large when the presented prime was PCA words (intra-language priming condition) compared to the other two cross-language conditions. Moreover, the priming effect was similar in the two cross-language conditions: equal translation priming effects for PCA targets presented by MSA or Hebrew primes. In the second experiment, the targets were PCA, MSA, or Hebrew words and the primes were always in PCA. The Arabic-Hebrew bilinguals reacted to the PCA targets more accurately and faster than they reacted to the Hebrew and MSA targets. Moreover, the effect of priming within the PCA language was twice as large as the effect of priming between languages, with no difference in the cross-language priming (PCA-MSA vs. PCA-Hebrew priming). The authors compared the effect of cross-language priming in the two experiments and found it asymmetrical. The magnitude of priming from PCA primes to MSA or Hebrew targets was two times as large as the magnitude of priming from MSA or Hebrew primes to PCA targets, with no significant priming difference when the prime was presented in MSA or Hebrew, and the target was in the other language.

\footnotetext{
${ }^{2}$ In their early investigation, Ibrahim and Aharon-Peretz (2005) referred to Modern Standard Arabic as Literacy Arabic (LA) and colloquial Arabic as Spoken Arabic (SA).
} 
Based on these findings, Ibrahim and Aharon-Peretz concluded that MSA, like Hebrew, is an L2 for native speakers of Arabic. Their conclusions suggest that MSA and Hebrew words are weakly linked to their concepts compared to the PCA words. These results are compatible with the revised hierarchical model (RHM; Kroll \& Groot, 1997; Kroll \& Stewart, 1994). The model proposes that associating L2 target words to their meanings is slower and less efficient than associating L1 target words to their meanings, as L2 words are weakly related to their concepts (Kroll, 1993; Kroll \& Stewart, 1994). Additionally, an L2 prime triggers weaker semantic expectations, which could mediate activating its L1 translation equivalent at $1000 \mathrm{~ms}$ SOA. On the other hand, the slow and inefficient activation of L2 targets can take a better advantage of the more efficient priming induced by L1 words. The model also suggests a developmental shift from weak mapping and lexical mediation to direct mapping between L2 words and their concepts, with increasing fluency (Chen \& Leung, 1989; Kroll \& Curley, 1988; Tzelgov et al., 1990). In other words, RHM predicts that asymmetric magnitude effects of the semantic priming may be reconciled across individuals or within individuals across time, being determined by the bilingual's proficiency in their second languages.

In a more recent study, Boudelaa and Marslen-Wilson (2013) cast doubt on Ibrahim and Aharon-Peretz's (2005) proposal that MSA is an L2 for literate speakers of Arabic. Boudelaa and Marslen-Wilson conducted two morphological priming experiments: one for MSA words and the other for Spoken Tunisian Arabic (STA). The authors showed that word patterns and roots act as significant linguistic units both in MSA and STA word processing. They reported parallel root/word pattern priming effects in both varieties of Arabic. Furthermore, Boudelaa and MarslenWilson found that literate speakers of STA reacted to MSA words as fast as they reacted to STA when they combined the data from the two experiments into a single analysis. On the basis of these results, they concluded that MSA is not an L2 for literate native speakers of STA "despite the differences underlying the two varieties in terms of the productivity of their morphological systems, the age at which they are acquired, and the sociolinguistic context in which they are experienced" (p. 1469). Boudelaa and Marslen-Wilson concluded that STA has no processing advantage over MSA because when children learn an L2 early in their lives (before the critical age of puberty), they gain nativelike performance in that language (Birdsong, 1999; Isel et al., 2010), and MSA is a case in point. They also remarked that it is inappropriate to consider any local dialects of Arabic and MSA as L1 and L2, respectively, just because they have different sociolinguistic and functional contexts. That is, MSA and any dialectal Arabic are two varieties with both overlapping and complementary distribution. Finally, Boudelaa and Marslen-Wilson ascribe Ibrahim's findings to the difficult sociolinguistic situation of Palestinian Arabs in Israel, where Hebrew is the dominant language of education and public occasions. Thus, it is possible that Ibrahim and Aharon-Peretz's (2005) findings reflect some exceptional sociolinguistic situation, which cannot be generalized to the rest of the Arabic-speaking world. This possibility suggests reinvestigating Ibrahim and Aharon-Peretz's priming experiment on a different population of native speakers of Arabic, where the sociolinguistic situation of Arabic is more stable. The present study postulates two opposite general hypotheses. First, MSA is, in fact, an L2 for literate speakers of Arabic and some task or methodological discrepancies might be responsible for the stated controversy between the two reviewed studies. Alternatively, MSA is not an L2 for literate speakers of Arabic, and Arab citizens of Israel are exceptionally unbalanced PCA-MSA bilinguals.

\section{Research Hypotheses}

Based on the proposal that it is easier to access a target word when its semantic representation has already been activated by a semantically-related (i.e., translation) prime, this study postulates:

H1: Literate native speakers of Jordanian Arabic respond to spoken words of Arabic in a semantically-related condition faster than they respond to the same target words in a semantically unrelated condition, irrespective of the target language (JCA vs. MSA) or the stimulus type (intra-language vs. cross-language).

Based on the different ages at which the two varieties of Arabic are acquired/learned and their quantitative experience differences, this research hypothesizes:

H2: Literate native speakers of Jordanian Arabic react to the spoken target words of JCA faster than they react to the spoken target words of MSA in both unrelated intra-language and unrelated cross-language conditions.

Findings of earlier research concluded no lexical switching costs in isolated-word recognition (e.g., Caramazza \& Brones, 1980). Accordingly, the present study proposes the following hypothesis:

H3: Literate native speakers of Jordanian Arabic react to the spoken target words in the unrelated cross-language condition as fast as they react to the same spoken target words in the unrelated intra-language condition, regardless of the target language (JCA vs. MSA). 
As unbalanced bilinguals activate the meanings of their L1 words more strongly than they activate the meanings of their L2 words, this study postulates the following hypothesis:

H4: The magnitude of semantic priming is larger when the prime is presented in JCA and the target in MSA compared to the magnitude of priming when the prime is presented in MSA, and the target is in JCA. To put it another way, in cross-language priming, L1 words are more effective primes than L2 words are.

This hypothesis is based on the proposal that the concept of the target word is already fully activated when the prime is in L1 while it is partially activated when the prime is presented in L2. In this case, it is the language of the prime that plays the principal role in activating the semantics node and boosting the access to the same semantic node through the target word.

\section{Method}

\subsection{Participants}

Forty native speakers of North Jordanian Arabic participated in this experiment. The participants were undergraduate students from Yarmouk University, located in the north of Jordan. All of the chosen participants had completed at least 12 years of formal education in Modern Standard Arabic. The participants had been recruited via flyers posted in public settings at the university and received monetary compensation for their participation. None of the participants reported any hearing deficit, nor did they take part in the other three experiments.

\subsection{Materials and Design}

A subset of the words used in the present experiment was adapted from the list of words that Ibrahim and PeretzAharon (2005) used in their early work. ${ }^{3}$ The present experiment reproduced the MSA words that have the same translation equivalents in both PCA and JCA after accommodating their colloquial translations to the phonology of the northern dialect of JCA. There were a total of 12 replicated stimuli. The present experiment included 28 other MSA words with their JCA translation equivalents. All of the related pairs were chosen to be unique noncognate translations, with clear difference in their phonological forms(e.g., MSA: ћaqiibah, JCA: fanteh 'suitcase').

The participants reacted to 80 target words and 80 target pseudowords of Arabic. Half of the target words were MSA words, and the other 40 words were their JCA translation equivalents. Since there were only two tested languages/varieties in the context of this study, I merged Ibrahim and Peretz-Aharon's (2005) two experiments into one single task. This helps us compare the magnitude of cross-language priming directly within the same participant rather than between two groups of participants. Each MSA and JCA target word was paired with four types of primes: intralanguage semantically unrelated prime, intra-language semantically related prime, cross-language semantically unrelated prime, and cross-language semantically related prime. Table 1 demonstrates the eight different tested conditions. In the semantically unrelatedconditions, the prime words resembled the targets in their frequency, concreteness, and structure. The stimuli were rotated across eight different lists so that none of the participants would listen to the same word (neither as a target nor as a prime) more than once.

\section{Table 1. Sample Stimuli, JCA and MSA Targets and Primes in Semantically related and Unrelated} Conditions

\begin{tabular}{|c|c|c|c|c|}
\hline Target & \multicolumn{2}{|c|}{ Related Prime } & \multicolumn{2}{|c|}{ Unrelated Prime } \\
\hline & JCA & MSA & JCA & MSA \\
\hline JCA:Santeh & Santeh & haqiibah & Jubaak & naafiðah \\
\hline suitcase & suitcase & suitcase & window & wodniw \\
\hline MSA:ћaqiibah & Janteh & ћaqiibah & Jubaak & naafiðah \\
\hline suitcase & suitcase & suitcase & window & window \\
\hline
\end{tabular}

Table 2 gives the average durations of the prime and target words in both MSA and JCA words. A comparison between the JCA and MSA primes suggests that any potential less effective priming for the MSA words compared to the JCA words might not be just because they have less average durations.

\footnotetext{
${ }^{3}$ In their early investigation, Ibrahim and Aharon-Peretz (2005) referred to Modern Standard Arabic as Literacy Arabic (LA) and colloquial Arabic as Spoken Arabic (SA).
} 
Table 2. Means and Standard Deviations of the Prime and Target Word Durations in Milliseconds.

\begin{tabular}{clcc}
\hline \multicolumn{2}{c}{ Prime } & \multicolumn{2}{c}{ Target } \\
\hline JCA & MSA & JCA & MSA \\
$649 \mathrm{~ms}$ & $648 \mathrm{~ms}$ & $660 \mathrm{~ms}$ & $654 \mathrm{~ms}$ \\
$(118)$ & $(116)$ & $(133)$ & $(119)$ \\
\hline
\end{tabular}

The target pseudowords were derived from real JCA and MSA words by changing one or two of their sounds. The resultant non-words were phonologically legal in one or both varieties of Arabic. The pseudoword followed a priming word of either variety of Arabic. Thirty judges from the same student population, who did not participate in the main experiment, were aurally presented with a list of the pre-designated MSA words. The judges were asked to sign into an online questionnaire, listen to a set of MSA words, and to suggest for each presented word the best translation in the JCA variety of Arabic. Each word was associated with its best translation equivalent that achieves the greatest consensus among the judges. The lexical database for Modern Standard Arabic (Aralex, Boudelaa \& Marslen-Wilson, 2010) provided the tested MSA words with their surface frequencies. The absence of reliable frequency norms for JCA was less problematic in this experiment. Since the JCA words used in this experiment were the best translations for their MSA equivalents, it was assumed that the frequencies of the concepts' translation to MSA and JCA words are similar. ${ }^{4}$

\subsection{Procedure and Apparatus}

The participants listened to a prime word followed by a target word or pseudoword. The stimulus onset asynchrony (SOA; the time allotted between the beginning of the prime and the target onset) was $1000 \mathrm{~ms}$. The experiment asked the participants to judge whether the second string of sounds (i.e., the target item) was a real or nonsense word by pressing a YES or NO key. The participants were asked to respond to the target as quickly and accurately as possible. The dominant hand always made the YES response. The instructions emphasized that the target word could be in JCA or MSA. Reaction times (RTs) and response accuracy were collected via a SONY portable computer PC (CPU 2.40 GHZ) running Windows 7 and E-prime 2.0 presentation software (Psychological Software Tools, Inc., Pittsburgh, PA, USA; http://www.pstnet.com). The computer reported RTs from the onset of the target. There was an interval of 2000 $\mathrm{ms}$ separating subject's last response from the next stimulus. The primes and the targets were presented over headphones at a comfortable sound level.

The participants were tested on only one experimental list and began the experiment with a block of 10 practice trials. Each experimental session lasted approximately 20 minutes. The participants were tested individually in a quiet room. The stimuli were recorded in a sound-attenuated booth with a PMD660 Marantz digital voice-recorder. The speaker was a male native speaker of Jordanian Arabic who speaks the same local dialect of the population and has received his school education in the Arabic language.

\section{Results}

No items or subjects were excluded as a result of excessive error rates. Forty-eight incorrect responses (3\% of the observations) were removed from the latency analysis. Visual inspection of the distribution of reaction times (RTs) by subjects showed that RTs longer than $1500 \mathrm{~ms}$ and shorter than $625 \mathrm{~ms}$ were proper upper and lower limits between outliers and the other responses. Thirty-five outliers ( $0.2 \%$ of the data) were discarded from the latency analysis.

To test the research hypotheses, I submitted the data to a mixed-effects model using language R, version 3.2.3 with lme4 (Bates et al., 2016) and lmerTest (Kuznetsova et al., 2016) packages. The mixed-effects model treated reaction times (RTs), measured in milliseconds, as the dependent variable. Participants, prime and target items were also incorporated into the model as random effects.

Two types of target words, two types of stimulus conditions, and two semantic relatedness conditions created a threefactor design. The predictors were the target language (MSA vs. JCA), the stimulus type (intra-language vs. crosslanguage), and the semantic relatedness (related vs. unrelated). To reduce any background noise in statistical analysis, the model incorporated word frequency, UP, and word duration as nuisance variables.

\footnotetext{
${ }^{4}$ Yet, I should admit that this method of frequency measures is not optimal. Written and spoken languages/varieties tend to deal with different topics and refer to different things. So almost any written-language corpus count is going to overestimate the spoken-language frequency of words like "president" and "mineral" and underestimate the frequency of "cup" and "please". Future research should revisit and address this issue.
} 


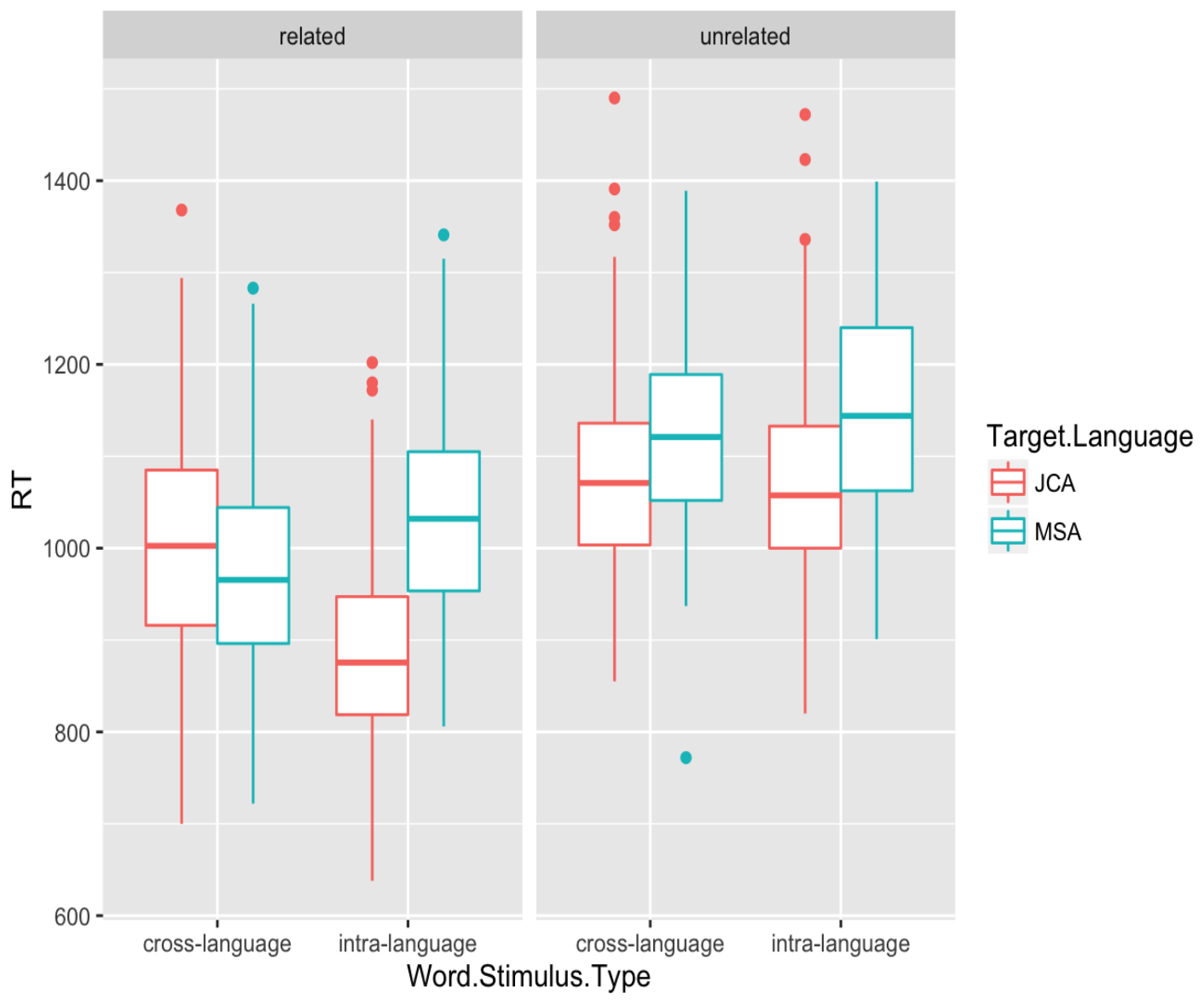

Figure 1. RT by language of the target word, stimulus type, and semantic relatedness

Figure 1 shows that participants' average response to the target words in the semantically-related condition was faster than their average response to the same target words in the semantically unrelated condition. The boxplots also demonstrate that this priming effect was pervasive, depending neither on the language of the primes nor the language of the targets. Inferential statistics, listed in Table 3, validated this finding. It revealed that when other factors were held constant (i.e., when both the prime and the target were presented in JCA, with zero frequency, zero UP, and zero word duration), participants' mean RT to the semantically-related targets was significantly $(p<0.0001)$ smaller than their mean RT to the semantically unrelated targets by $183 \mathrm{~ms}$. The nature of the interactions (listed in Table 3 ) and their directions (shown in Figure 1) indicate that both the language of the target and the language of the prime depend on the level of semantic relatedness, but not vice versa. These findings are consistent with the first research hypothesis, which predicts semantic priming effects irrespective of stimulus type or target language.

Table 3. Summary of the Mixed-effects Model for Both Categorical and Continuous Variables Predicting RTs to Target Words.

\begin{tabular}{lcccc}
\hline Fixed effect & Estimate & SE & $t$ & $p(t)$ \\
\hline Intercept & & & & \\
Relatedness: related & 982 & 23.3 & 42.1 & $<0.0001$ \\
Target language: MSA & -183 & 14.0 & 13.0 & $<0.0001$ \\
Stimulus type: cross-language & 77 & 14.3 & 5.4 & $<0.0001$ \\
Target language: MSA*Stimulus type: cross- & -28 & 14.0 & 0.5 & 0.5721 \\
language & & 24.6 & -1.1 & 0.2603 \\
Relatedness: related* Target language: MSA & 66 & 19.8 & 3.3 & $<0.0001$ \\
Relatedness: related* Stimulus type: cross-language & 115 & 19.8 & 5.8 & $<0.0001$ \\
Relatedness: related* Target language: MSA* & -161 & 34.7 & -4.6 & $<0.0001$ \\
Stimulus type: cross-language & & & & \\
Log frequency & -9.3 & 2.2 & -4.1 & $<0.0001$ \\
UP & 0.1 & 0.03 & 3.8 & 0.0003 \\
Target word duration & 0.08 & 0.03 & 2.3 & 0.0269 \\
\hline
\end{tabular}


The right panel of Figure 1 indicates longer RTs to MSA targets relative to JCA targets in both unrelated intra-language and unrelated cross-language conditions. The same panel shows no average response difference between the unrelated intra-language and the unrelated cross-language conditions, irrespective of the language of the target word. Results of the mixed-effect model revealed that participants significantly $(p<0.0001)$ slowed their RTs to the MSA targets in the unrelated intra-language condition compared to the JCA targets in the unrelated intra-language condition by, on average, $77 \mathrm{~ms}$. The model yielded no significant difference on average RTs between the intra-language and crosslanguage condition when the other fixed effects were held constant (i.e., when JCA is the target language of the unrelated condition, with zero frequency, zero UP and zero word duration, $p=0.6$ ). The mixed-effects model did not reveal a significant interaction between the language of the target and stimulus type in the semantically unrelated conditions $(p<0.26)$. These results agree with the second hypothesis: in the semantically unrelated condition, native speakers of Jordanian Arabic react to JCA targets faster than they react to MSA targets, no matter in what variety of Arabic the prime is presented. The data also concur with the third research hypothesis: native speakers of Jordanian Arabic react to the target words of Arabic in the unrelated language-consistent condition as fast as they react to the same target words in the unrelated language-inconsistent condition, irrespective of the language of the target.

However, the significant interactions between semantic relatedness and target language, and semantic relatedness and stimulus type suggest that the influences of the target language and stimulus type on RTs were not straightforward, but depended on the level of relatedness. As the Figure 1 indicates, the difference between the unrelated intra-language JCA condition (mean $=982$ ) and the related intra-language JCA condition (mean $=799)$ is greater than the difference between the unrelated intra-language MSA condition (mean = 1059) and the related intra-language MSA condition (mean = 942). The significant two-way interaction between relatedness and the target language, shown in Table 3, confirms this difference in the magnitude of semantic priming. Figure 1 also depicts that the RTs difference between the unrelated intra-language JCA condition (mean $=982)$ and the related intra-language JCA condition $($ mean $=799)$ is larger than the RTs difference between the unrelated cross-language JCA condition $($ mean $=1000)$ and the related cross-language JCA condition (mean $=922)$. ${ }^{5}$ The significant two-way interaction between relatedness and stimuli type validates this difference in the magnitude of priming. Moreover, Figure 1 shows that the RTs difference between the unrelated cross-language MSA condition (mean $=1039)$ and the related cross-language MSA condition $($ mean $=876)$ is twice as large as the RTs difference between the unrelated cross-language JCA condition (mean $=1000)$ and the related cross-language JCA condition ( mean $=922$ ).

The significant three-way interaction between relatedness, target language and stimulus type $(p<0.0001)$, given in Table 3, confirms this difference in the magnitude of semantic priming. The data analysis supports the fourth hypothesis of the research: the priming effect between JCA primes and MSA targets is larger than the priming effect between MSA primes and JCA targets.

\section{Discussion}

This study replicated Ibrahim and Peretz-Aharon's early translation priming experiment on a different group of Arabicdiglossic speakers. The tested participants were Jordanian rather than Israeli native speakers of Arabic. The priming experiment of this study revealed four main findings. First, literate native speakers of Jordanian Arabic react to Arabic

\footnotetext{
${ }^{5}$ These numbers can be calculated by adding together the Estimate Coefficients, given in the first column of Table 3 . The intercept is the average RTs to the basic level (i.e., the unrelated intra-language JCA condition when the values of the other continuous variables are zero $=\mathbf{9 8 2} \mathbf{~ m s}$ ). The average RTs to the related intra-language $\mathbf{J C A}=$ intercept + relatedness: related $=982-183=\mathbf{7 9 9} \mathbf{m s}$. Similarly, the average RTs to the unrelated intra-language MSA condition $=$ intercept + target language: $M S A=982+77=\mathbf{1 0 5 9} \mathbf{~ m s}$. The average RTs to the unrelated cross-language JCA condition $=$ intercept + stimulus type: cross-language $=982+8=\mathbf{1 0 0 0} \mathbf{~ m s}$. The mean RTs to the unrelated cross-language MSA condition= intercept + target language: $M S A+$ stimulus type: cross-language + target language: MSA * stimulus type: cross-language $=982+77+8-28=\mathbf{1 0 3 9}$. The average $\mathrm{RTs}$ to the related intra-language MSA condition $=$ intercept + relatedness: related + target language: MSA + relatedness: related $*$ target language: MSA $=982-183+77+66=\mathbf{9 4 2} \mathbf{~ m s}$. The mean RTs to the related cross-language JCA condition $=$ intercept + relatedness: related + stimulus type: crosslanguage + relatedness: related $*$ stimulus type: cross-language $=982-183+8+115=\mathbf{9 2 2} \mathbf{~ m s}$. The average RTs to the related cross-language MSA condition = intercept + relatedness: related + target language: $M S A+$ stimuli type: crosslanguage + target language: MSA * stimulus type: cross-language + relatedness: related * target language: MSA + relatedness: related $*$ stimulus type: cross-language + relatedness: related $*$ target language: MSA $*$ stimulus type: crosslanguage $=982-183+77+8-28+66+115-161=876$. Now the priming effect between any two conditions can be easily obtained. For example, the priming effect for the cross-language JCA condition $=1000-922=78$, and the priming effect for the cross-language MSA condition $=1039-876=163$. The priming effect difference between JCA and MSA targets in the cross-language condition $=163-78=85$.
} 
target words in the semantically-related condition faster than they react to the same target words in the semantically unrelated condition. Second, when prime and target words are semantically unrelated, native speakers of Jordanian Arabic respond to JCA targets faster than they react to MSA targets. Third, native speakers of Jordanian Arabic demonstrate no switching cost between pairs of unrelated cross-language words and pairs of unrelated intra-language words. Fourth, JCA words are good primes for MSA targets, but MSA primes are not that good for JCA targets. These results suggest a stronger overall activation/connection between JCA words and their semantics. The bidirectional priming effects for both varieties of Arabic suggest that their translation equivalents share the same semantic network, similar to early bilinguals. The asymmetrical priming effects indicate that JCA lexical items are more integrated into the semantic representations compared to MSA lexical items, similar to sequential bilingualism.

Results of this experiment suggest that literate native speakers of Jordanian Arabic process the vocabulary of JCA and MSA the same way unbalanced bilinguals process the vocabulary of their L1s and L2s in similar experiments (Kroll, 1993; Kroll \& Stewart, 1994). For example, Schoonbaert et al. (2009) conducted two masked-priming translation experiments on two similar groups of unbalanced Dutch-English bilinguals. Results of the two experiments showed significant translation priming from L1 to L2 (meisje-girl) and from L2 to L1 (girl-meisje) at two different SOAs (i.e., $250 \mathrm{~ms}$ and $100 \mathrm{~ms}$ ). The translation priming was asymmetrical: there were stronger translations priming effects from L1 to L2 than from L2 to L1.

The present study reproduced results of Ibrahim and Peretz-Aharon's original work on Palestinian Arabic-Hebrew bilinguals. To determine whether MSA is a second language to Arabic speakers, Ibrahim and Aharon-Peretz (2005) compared semantic priming effects in the auditory lexical decision of spoken Palestinian Arabic, MSA, and Hebrew (an L2 to all participants). Primes were either in MSA or in Hebrew and the targets were in PCA, and vice versa. The priming effects from PCA primes to MSA or Hebrew targets were double the priming effects from MSA or Hebrew primes to PCA targets. Moreover, the priming effect was three times as large when both the prime and the target were PCA compared to MSA or Hebrew primes and no difference between Hebrew and MSA primes was found.

All these results are predicted in light of the revised hierarchical model (RHM; Kroll \& Groot, 1997; Kroll \& Stewart, 1994). The model argues that concepts are more strongly linked to their phonological representations in L1 than in L2. If we assume that L2 words can address the semantic system directly but weakly, then activating their semantic representations will be less efficient. As a result, the amount of activation that spreads from an L1 prime to an L2 target is more than the amount of activation that spreads from an L2 prime to an L1 target. In the present study, what may cause the difference in the priming effect is the strength of activation from the semantic node to the lexical nodes rather than the speed of building up the word nodes of the primes. Note that, on average, $1060 \mathrm{~ms}$ was enough time for the participants to recognize an MSA target, make an executive decision about its lexicality, and physically move their finger to press a button. Accordingly, the one-second SOA (i.e., the time between the onset of the prime and the onset of the target) seems to be enough time to activate the lexical nodes of the MSA primes as robust cohort competitors. The proposed account is consistent with Weber and Cutler's (2004) findings. That study analyzed the proportions of their participants' visual fixation on a target picture, compared to other three-distractor pictures, when they listen to its English word. The researchers observed that, by1000 ms, both their English monolingual speakers and their professional Dutch-English bilinguals looked more often at the target picture relative to the distractors. However, the monolingual had more fixations on the target pictures (95\%) compared to the Dutch-English bilinguals (80\%). Weber and Cutler concluded that lexical completion is greater for non-native than for native listeners.

The results suggest that despite native Arabic speakers' intensive daily use of MSA when dealing with written language and spoken language in formal situations, MSA remains as a second language for diglossic speakers of Arabic. Reproducing Ibrahim and Peretz-Aharon's findings on a more stable population of Arabic diglossia casts doubt on Boudelaa and Marslen-Wilson's (2013) proposal that Ibrahim and Aharon-Peretz's (2005) findings may reflect some exceptional sociolinguistic situation that cannot be generalized to the rest of the Arabic-speaking world. The question of why Boudelaa and Marslen-Wilson's findings disagreed with Ibrahim and Aharon-Peretz's results, reproduced in this study, is still open for further investigation. It is possible that some methodological matters were responsible for these inconsistencies. Alternatively, the mixed results could be due to some discrepancies in the pedagogical strategies of teaching Arabic among the Arab states. Psycholinguistic research on bilingualism emphasizes that the speed of access to semantic representation is not limited to language proficiencies and the context of acquisition, but also affected by item characteristics, such as concreteness and cognates (De Groot, 1992a; 1992b; 1995; Van Hell, 1998; Van Hell \& De Groot, 1998). For example, Van Hell and De Groot (1998) reported that bilinguals demonstrate stronger priming effects between cross-language concrete nouns and cognates (i.e., words sharing meaning and cluster of sounds in different languages) compared to cross-language abstract nouns and non-cognates. Their results agree with the distributed feature modelof bilingual semantics (De Groot, 1992a; 1995; Van Hell \& De Groot, 1998). This model predicts that the semantic representations for concrete nouns and cognate translations are nearly similar across 110 
languages while abstract nouns and non-cognates translations are more distinct. This explanation is based on De Groot and colleague's proposal that both concrete and cognate translation equivalents share more distributed meaning and semantic overlap compared to abstract and non-cognate translation equivalents. In a more recent study, Ibrahim (2006) found greater priming effects when PCA/Hebrew primes and MSA targets were cognate translations than when they were non-cognate translations. However, neither the current study nor Ibrahim and Aharon-Peretz's original work examined the effects of concreteness on cross-language priming of Arabic words. Effects of concreteness can be a topic of further future research, especially if a reliable objective measure for Arabic word concreteness is employed.

Finally, this study suggests that diglossic speakers of Arabic do not experience switching costs when they listen to cross-language stimuli of Arabic compared to intra-language stimuli. The data from the present study showed no delay in accessing the target words that follow semantically unrelated words from the other lexicon (i.e. the other variety of Arabic), compared to the same target words following semantically unrelated words from the same lexicon (i.e. the same variety of Arabic).This finding concurs with the view of that bilinguals keep the lexicon of the other language activated in language processing (e.g. Thomas \& Allport, 2000; von Studnitz \& Green, 2002).

\section{References}

Abu-Rabia, S. (2000). Effects of exposure to literary Arabic on reading comprehension in a diglossic situation. Reading and Writing, 13(1-2), 147-157.

Al-Khatib, M., \& Sabbah, A. E. H. (2008). Language choice in mobile text messages among Jordanian university students. SKY Journal of Linguistics, 21, 37-65.

Al-Sughayer, K. I. (1990). Aspects of comparative Jordanian and modern standard Arabic phonology [Abstract]. Linguistics and Language Behavior Abstracts (LLBA).

Amara, M. (2006, October). The vitality of the Arabic language in Israel from a sociolinguistic perspective. Dalah's Newsletter, 29,1-11.

Bates, D. Maechler, M., Bolker, B., \& Walker, S. (2016). lme4: Linear mixed-effects models using Eigen and S4. R package version 1.1-8, http://CRAN.R-project.org/package=lme4.

Birdsong, D. (1999). Introduction: Whys and why nots of the critical period hypothesis for second language acquisition. In D. Birdsong (Ed.), Second language acquisition and the critical period hypothesis (pp. 1-21). Mahwah, NJ :Lawrence Erlbaum.

Boudelaa, S., \& Marslen-Wilson, W. (2010). Aralex: A lexical database for modern standard Arabic. Behavior Research Methods, 42(2), 481-487.

Boudelaa, S., \& Marslen-Wilson, W. (2013). Morphological structure in the Arabic mental lexicon: Parallels between standard and dialectal Arabic. Language and Cognitive Processes, 28(10), 1453-1473.

Caramazza, A., \& Brones, I. (1980). Semantic classification by bilinguals. Canadian Journal of Psychology/Revue Canadienne De Psychologie, 34(1), 77-81.

Chen, H., \& Leung, Y. (1989). Patterns of lexical processing in a non-native language. Journal of Experimental Psychology: Learning, Memory, and Cognition, 15(2), 316-325.

De Groot, A. (1992a). Determinants of word translation. Journal of Experimental Psychology: Learning, Memory \& Cognition 18, 1001-1018.

De Groot, A. (1992b). Bilingual lexical representation: A closer look at conceptual representation. In R. Frost, \& L. Katz (Eds.), Orthography, Phonology, Morphology, and Meaning (pp. 389-412). Amsterdam: Elsevier.

Ferguson, C. (1959). Diglossia. Word, 15, 325-340.

Finkbeiner, M., Forster, K., Nicol, J., \& Nakamura, K. (2004). The role of polysemy in masked semantic and translation priming. Journal of Memory and Language, 51(1), 1-22.

Green, D. (1998). Mental control of the bilingual lexico-semantic system. Bilingualism: Language and Cognition, 1(2), 67-104.

Holes, C. (2004). Modern Arabic; structures, functions, and varieties. London and New York: Longman.

Ibrahim, R. (2006). Do languages with cognate relationships have advantages in second language acquisition? The Linguistics Journal, 1(3), 66-96.

Ibrahim, R. (2009). The cognitive basis of diglossia in Arabic: Evidence from a repetition priming study within and between languages. Psychology Research and Behavior Management, 2, 93-105.

Ibrahim, R., \& Aharon-Peretz, J. (2005). Is literary Arabic a second language for native Arab speakers?: Evidence from semantic priming study. Journal of Psycholinguistic Research, 34(1), 51-70.

Isel, F., Baumgaertner, A., Thraen, J., Meisel, J., \& Buechel, C. (2010). Neural circuitry of the bilingual mental lexicon: Effect of age of second language acquisition. Brain and Cognition, 72(2), 169-180. 
Jiang, N. (1999). Testing processing explanations for the asymmetry in masked cross-language priming. Bilingualism: Language and Cognition, 2(1), 59-75.

Jiang, N., \& Forster, K. (2001). Cross-language priming asymmetries in lexical decision and episodic recognition. Journal of Memory and Language, 44(1), 32-51.

Kroll, J. (1993). Accessing conceptual representations for words in a second language. In R. Schreuder, \& B. Weltens (Eds.), The bilingual lexicon (pp. 53-81). Amsterdam, The Netherlands: John Benjamins Publishing Company.

Kroll, J., \& Curley, J. (1988). Lexical memory in novice bilinguals: The role of concepts in retrieving second language words. In M. Gruneberg, P. Morris, \& R. Sykes (Eds.), Practical aspects of memory (volume 2) (pp. 389-395). London: Wiley.

Kroll, J., \& De Groot, A. (1997). Lexical and conceptual memory in the bilingual: Mapping form to meaning in two languages. Tutorials in bilingualism: Psycholinguistic perspectives (pp. 169-199). Mahwah, NJ: Lawrence Erlbaum Associates Publishers.

Kroll, J., Michael, E., Tokowicz, N., \& Dufour, R. (2002). The development of lexical fluency in a second language. Second Language Research, 18(2), 137-171.

Kroll, J., \& Stewart, E. (1994). Category interference in translation and picture naming: Evidence for asymmetric connections between bilingual memory representations. Journal of Memory and Language, 33(2), 149.

Kuznetsova, A., Brockhoff, P. \& Christensen, R. (2016). lmerTest: Tests in linear mixed effect models. Version 2.0-25. Retrieved from: http://cran.r project.org/web/packages/lmerTest/lmerTest.pdf

Laks, L., Berman, R. A. (2014). A new look at diglossia: Modality-driven distinctions between spoken and written narratives in Jordanian Arabic. In E. Saiegh-Haddad \& R. Malatesha Joshi (Eds.), Arabic literacy: Theoretical insights and practical challenges (pp. 241-254). Dordrecht: Springer.

Maamouri, M. (1998). Arabic diglossia and its impact on the quality of education in the Arab region, A paper presented at The World Bank Mediterranean Development Forum, Marrakech, Morocco, September 3-6, 1998.

Mostari, H. A. (2009). What do mobiles speak in Algeria? Evidence from language. Current Issues in Language Planning, 10, 377-386.

Sabourin, L., Brien, C., \& Burkholder, M. (2014). The effect of age of L2 acquisition on the organization of the bilingual lexicon: Evidence from masked priming. Bilingualism: Language and Cognition, 17(3), 542-555.

Schoonbaert, S., Duyck, W., Brysbaert, M., \& Hartsuiker, R. (2009). Semantic and translation priming from a first language to a second and back: Making sense of the findings. Memory \& Cognition, 37(5), 569-586.

Schoonbaert, S., Holcomb, P., Grainger, J., \& Hartsuiker, R. (2011). Testing asymmetries in noncognate translation priming: Evidence from RTs and ERPs. Psychophysiology, 48(1), 74-81.

Suleiman, S. M. (1985). Jordanian Arabic between diglossia and bilingualism: Linguistic analysis. Pragmatics and Beyond, 6(8), 1-131.

Talamas, A., Kroll, J., \& Dufour, R. (1999). From form to meaning: Stages in the acquisition of second-language vocabulary. Bilingualism: Language and Cognition, 2(1), 45-58.

Thomas, M., \& Allport, A. (2000). Language switching costs in bilingual visual word recognition. Journal of Memory and Language, 43(1), 44-66.

Tzelgov, J., Henik, A., \& Leiser, D. (1990). Controlling the stroop interference: Evidence from a bilingual task. Journal of Experimental Psychology: Learning, Memory and Cognition, 16, 760-771.

Van Hell, J. (1998). Cross-language processing and bilingual memory organization. (Unpublished doctoral dissertation). University of Amsterdam, Amsterdam.

Van Hell, J., \& De Groot, A. (1998). Conceptual representation in bilingual memory: Effects of concreteness and cognate status in word association. Bilingualism: Language and Cognition, 1(3), 193-211.

von Studnitz, R., \& Green, D. (2002). The cost of switching language in a semantic categorization task. Bilingualism, $5(3), 241-251$.

Weber, A., \& Cutler, A. (2004). Lexical competition in non-native spoken-word recognition. Journal of Memory and Language, 50(1), 1-25. 